\title{
FERRAMENTAS MATEMÁTICAS, SUSCETIBILIDADE MAGNÉTICA E MODELOS DE PAISAGEM APLICADOS NA DELIMITAÇÃO DE ÁREAS DE MANEJO ESPECÍFICO
}

\author{
Sammy Sidney Rocha Matias ${ }^{(1)^{*}}$, José Marques Júnior ${ }^{(2)}$, Gener Tadeu Pereira ${ }^{(3)}$ e Diego \\ Silva Siqueira ${ }^{(4)}$
}

(1) Universidade Estadual do Piauí, Campus Dep. Jesualdo Cavalcanti Barros, Departamento de Agronomia, Corrente, Piauí, Brasil.

(2) Universidade Estadual Paulista, Faculdade de Ciências Agrárias e Veterinárias, Departamento de Solos e Adubos, Jaboticabal, São Paulo, Brasil.

(3) Universidade Estadual Paulista, Faculdade de Ciências Agrárias e Veterinárias, Departamento de Ciências Exatas, Jaboticabal, São Paulo, Brasil.

(4) Universidade Estadual Paulista, Faculdade de Ciências Agrárias e Veterinárias, Departamento de Solos e Adubos, Programa de Pós-graduação em Agronomia (Ciência do Solo), Jaboticabal, São Paulo, Brasil.

* Autor correspondente.

E-mail: ymmsa2001@yahoo.com.br

\section{RESUMO}

A identificação de padrões de variabilidade dos atributos do solo permite o uso e a ocupação do solo de maneira sustentável. O objetivo deste trabalho foi delimitar áreas de manejo específico utilizando ferramentas matemáticas, suscetibilidade magnética e modelos de paisagem. A área de estudo localiza-se no município de Guariba, SP. Escolheu-se uma área de 110 ha, onde foram identificadas e mapeadas três superfícies geomórficas (I, II e III). Na área, foram coletadas 204 amostras de solo em uma transeção, nas profundidades de 0,00-0,20 e 0,60-0,80 m. Foram determinados o $\mathrm{pH} \mathrm{em} \mathrm{CaCl}_{2}$, os teores de areia, argila, matéria orgânica, $\mathrm{P}, \mathrm{Ca}, \mathrm{Mg}, \mathrm{K}, \mathrm{H}+\mathrm{Al}$, e calculados SB, CTC e V. A suscetibilidade magnética (SM) foi medida com o auxílio de uma balança analítica. Os limites matemáticos da técnica Split Moving Windows Dissimilarity Analysis (SMWDA) utilizando as informações da suscetibilidade magnética ficaram próximos aos limites de campo identificados com base nos modelos de paisagem. A utilização conjunta da suscetibilidade magnética, dos modelos matemáticos e de paisagem permitiu identificar diferentes áreas de manejo, locais com diferentes teores de argila e níveis de fertilidade do solo. A susceptibilidade magnética pode ser adotada como alternativa para identificar e mapear unidades de manejo. 
Palavras-chave: superfície geomórfica, estatística multivariada, Split Moving Windows.

\title{
ABSTRACT: MATHEMATICAL TOOLSASSOCIATED WITH MAGNETIC SUSCEPTIBILITY AND LANDSCAPE MODELS IN IDENTIFYING AREAS FOR SPECIFIC MANAGEMENT PRACTICES
}

\begin{abstract}
The identification of variability patterns through soil properties allows land use and occupation in a sustainable manner. The aim of this study was to ascertain the potential of magnetic susceptibility of the soil and landscape models in defining areas for specific management practices through the use of mathematical tools. The study area is in the municipality of Guariba, SP, Brazil. We chose an area of 110 ha in which three geomorphic surfaces (I, II, and III) had been identified and mapped. In this area, we collected 204 soil samples in a transect at depths of 0.00-0.20 and 0.60-0.80 m. We determined $\mathrm{pH}$ in $\mathrm{CaCl}_{2}$, and quantified the contents of sand and clay, organic matter, $\mathrm{P}, \mathrm{Ca}, \mathrm{Mg}, \mathrm{K}, \mathrm{H}+\mathrm{Al}$, and calculated $B S, C E C$, and V. Magnetic susceptibility (MS) was measured with the aid of an analytical balance. The mathematical limits of the split moving-windows dissimilarity analysis (SMWDA) technique, using the information from magnetic susceptibility, coincided with the field boundaries identified based on the landscape models. The combined use of magnetic susceptibility, mathematical modeling, and landscape models allowed faster and less expensive identification of different management areas, locations with different levels of clay content and soil fertility levels. Magnetic susceptibility may be adopted as an alternative for identification and mapping of management units.
\end{abstract}

Keywords: geomorphic surface, multivariate statistics, split moving windows.

\section{INTRODUÇÃO}

O uso e a ocupação do solo de maneira sustentável levando em conta a variabilidade dos atributos do solo permitem um retorno econômico para o produtor e consequentemente ao meio ambiente. Pesquisas recentes sobre o desenvolvimento de indicadores de impactos globais do uso e da ocupação do solo (Santos et al., 2011; Sousa et al., 2012; Matias et al., 2013) evidenciam a necessidade de informações mais detalhadas e menos subjetivas.

Nesse contexto, vários trabalhos têm apresentado nova abordagem na caracterização detalhada dos atributos do solo, associando ferramentas de classificação numérica, entre elas a geoestatística, com informações do relevo e dos modelos de paisagem (Cunha et al., 2005; Siqueira et al., 2010a; Campos et al., 2012a,b; Matias et al., 2013). Esta associação de métodos e procedimentos facilita a delimitação de áreas de manejo específico e consequentemente o gerenciamento das atividades agrícolas (Sanchez et al., 2012).

Além da geoestatística, destaca-se a técnica de classificação numérica conhecida por Split Moving Windows Dissimilarity Analysis (SMWDA), "Janela Móvel". É uma variação da análise geoestatística e foi desenvolvida com base no autocorrelograma, para identificar limites entre paisagem. Essa análise foi utilizada por Erdős et al. (2011, 2012) e Xu et al. (2012) para detectar os limites de compartimentos em razão de diferentes ecótonos em várias situações de campos.
$\mathrm{Na}$ ciência do solo, pesquisadores (Cunha et al., 2005; Ross e Sah, 2011; Espinar et al., 2011; Erdős et al., 2013) têm utilizado a SMWDA e outras ferramentas de classificação numérica para validar matematicamente os limites de campo entre diferentes compartimentos identificados com auxílio de modelos de paisagem.

A SMWDA requer que a coleta de amostras seja balizada pela transeção (espigão) (Erdôs et al., 2011, 2012). O processo relativamente simples da análise SMWDA, associado ao fato de a técnica de identificação da transeção ser uma etapa bastante conhecida pelos mapeadores, a torna uma ferramenta poderosa para validar limites de campo (Espinar et al., 2011; Xu et al., 2012; Erdős et al., 2013).

No campo, os limites entre as diferentes áreas de manejo podem ser identificados com base nos modelos de paisagem, entre eles o de segmento de vertente (Dalrymple et al., 1968) e superfícies geomórficas (Ruhe, 1969). Daniels et al. (1971) acrescentaram nessa definição que as superfícies geomórficas possuem limites geográficos definidos. Segundo Campos et al. (2012a), diferentes classes de solo, quando localizadas numa mesma superfície geomórfica, possuem o mesmo padrão de homogeneidade dos atributos do solo.

Porém, a classificação numérica para identificar limites de precisão entre classes de solo ou áreas de manejo específico (locais com variabilidade controladas, mais homogêneas quanto à fertilidade do solo e teor de argila, por exemplo) necessita de 
grande quantidade de amostras, o que dificulta sua utilização tanto pela pesquisa quanto pelo setor produtivo (Siqueira et al., 2010b; Espinar et al., 2011; Sanchez et al., 2012; Xu et al., 2012; Erdős et al., 2013; Matias et al., 2013). Assim, para que a utilização conjunta da classificação numérica e dos modelos de paisagem seja viável, são necessárias técnicas alternativas para quantificar os atributos do solo. Uma dessas técnicas é a medida da suscetibilidade magnética do solo (Souza Junior et al., 2010; Santos et al., 2011; Zawadzki et al., 2012; Matias et al., 2013; Siqueira et al., 2015).

A suscetibilidade magnética é um atributo do solo que reflete a composição de minerais nas diferentes frações do solo (Torrent et al., 2010; Siqueira et al., 2010b; Souza Junior et al., 2010; Matias et al., 2013). O mapeamento da suscetibilidade magnética vem se destacando como um método prático com diferentes aplicações na ciência do solo, como na pedogênese (Souza Junior et al., 2010; Torrent et al., 2010) e no auxílio da compartimentação da paisagem (Santos et al., 2011; Zawadzki et al., 2012; Matias et al., 2013).

Nesse contexto, o objetivo deste trabalho foi delimitar áreas de manejo específico utilizando ferramentas matemáticas, suscetibilidade magnética e modelos de paisagem.

\section{MATERIAL E MÉTODOS}

A área de estudo possui 110 ha e está localizada no município de Guariba, nordeste do Estado de São
Paulo. As coordenadas geográficas são $21^{\circ} 24^{\prime} \mathrm{S}$ e $48^{\circ} 09^{\prime} \mathrm{O}$ e possui altitude média de $630 \mathrm{~m}$ acima do nível do mar (Figura 1). O clima da região, segundo a classificação de Köppen, é do tipo mesotérmico, com inverno seco (Cwa), temperaturas variando entre 21 a $27{ }^{\circ} \mathrm{C}$, precipitação pluvial média de $1.400 \mathrm{~mm}$ e chuvas concentradas no período de novembro a fevereiro.

O relevo é considerado predominantemente plano a suave ondulado, com declividade variando de 3 a $8 \%$. A área está inserida no Planalto Ocidental paulista, no divisor litoestratigráfico arenitobasáltico (IPT, 1981). O material geológico na área estudada está relacionado aos arenitos do Grupo Bauru, Formação Adamantina, conforme o Instituto de Pesquisa Tecnológicas do Estado de São Paulo (IPT, 1981) e intrusões de lamito. A área é cultivada com cana-de-açúcar há 35 anos, já ocorridas as seguintes operações: renovação do canavial: subsolagem; erradicação química da soqueira; aplicação de $2 \mathrm{t} \mathrm{ha}{ }^{-1}$ de calcário dolomítico; $1 \mathrm{t} \mathrm{ha}^{-1}$ de gesso agrícola; adubação de plantio realizada na sulcação, sendo utilizado $500 \mathrm{~kg} \mathrm{ha}^{-1}$ da fórmula NPK 10-25-25 e o plantio realizado de forma manual; e a partir do segundo ano, adubação com aplicação de $100 \mathrm{~m}^{3}$ de vinhaça e $200 \mathrm{~kg} \mathrm{ha}^{-1}$ de nitrato de amônia aplicada superficialmente ao lado da linha de plantio. O mapa de solos da área de estudo registra a ocorrência do Latossolo VermelhoAmarelo distrófico típico textura média (LVAd), nas posições mais elevadas e planas, e Latossolo Vermelho distrófico típico textura média (LVd), no terço inferior da encosta na escala detalhada (1:12.000) (Embrapa, 2006).

Com o auxílio do modelo digital de elevação e observações de campo, foi identificada uma transeção

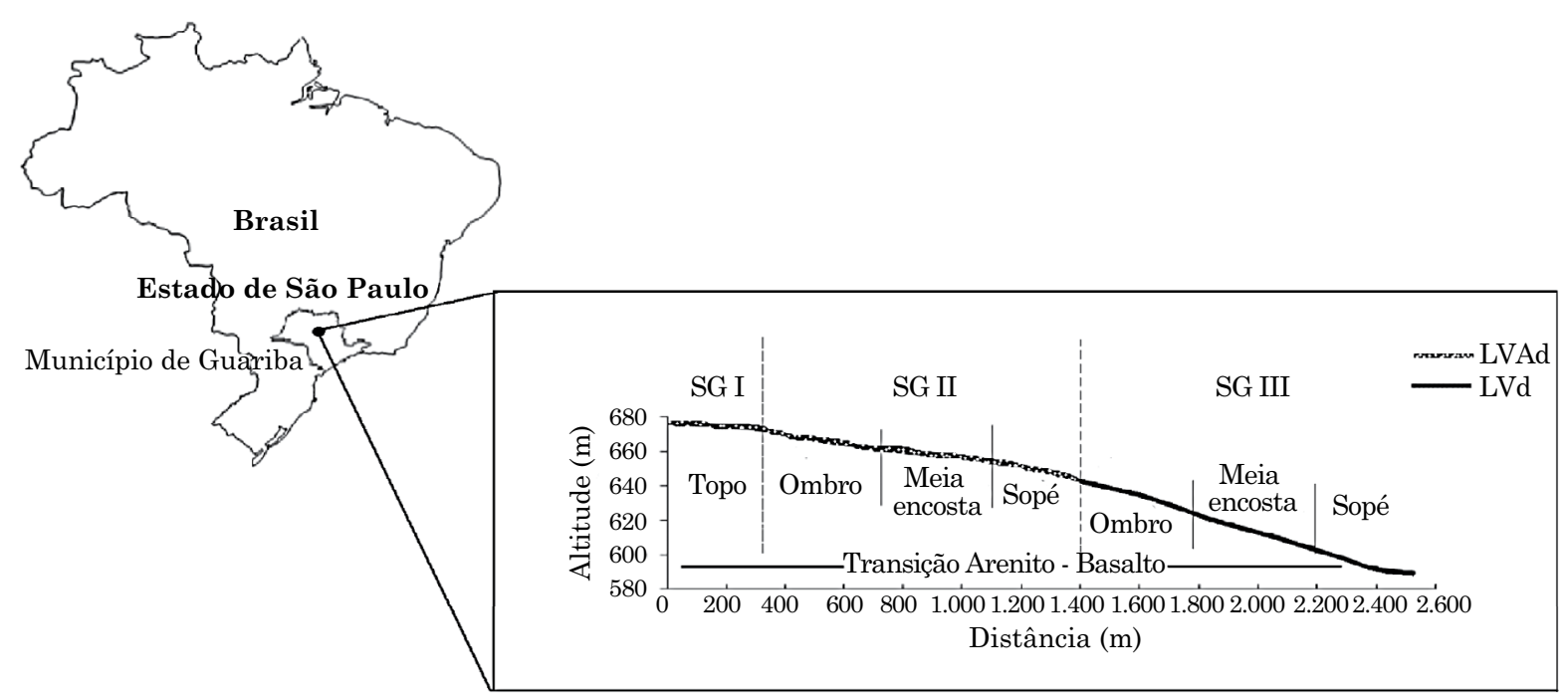

Figura 1. Localização da área e perfil altimétrico com a identificação das superfícies geomórficas (SG), segmentos de vertentes e solos (Latossolo Vermelho-Amarelo distrófico típico textura média = LVAd; e Latossolo Vermelho distrófico típico textura média $=$ LVd). 
de $2.700 \mathrm{~m}$ a partir do topo da vertente, seguindo o espigão até o sopé, no sentido do caimento mais suave do declive (Figura 1). Para identificar os limites das superfícies geomórficas no campo, foram realizadas observações com base nas mudanças das inclinações do terreno (Ruhe, 1969; Daniels et al., 1971), sendo delimitadas três superfícies geomórficas. Posteriormente, foram identificados os segmentos de vertentes de acordo com Dalrymple et al. (1968) (Figura 1). A superfície geomórfica I (SG I) é considerada a mais velha e de caráter deposicional, por possuir menor variabilidade em relação às demais superfícies geomórficas, tem uma extensão aproximada de $400 \mathrm{~m}$, com declividade variando de 0 a $4 \%$. As superfícies geomórficas II (SG II) e III (SG III) são consideradas erosionais, sendo a SG II plana com suave inclinação e a SG III com declividade mais acentuada $(7 \%)$, em relação às demais superfícies, que se estende até o fim da vertente (sopé). A extensão da SG II é $1.100 \mathrm{~m}$ e a SG III, $1.200 \mathrm{~m}$.

Ao longo da transeção, o terreno foi estaqueado e georreferenciado em intervalos regulares de $25 \mathrm{~m}$ e, nesses pontos, foram coletadas com trado amostras de solo nas profundidades de 0,00-0,20 e de 0,60-0,80 m, totalizando 204 amostras.

Nas amostras coletadas, foram determinadas a análise granulométrica pelo método da pipeta, utilizando uma solução de $\mathrm{NaOH} 0,1 \mathrm{~mol} \mathrm{~L}^{-1}$ como dispersante químico e a agitação mecânica em aparato de baixa rotação por $16 \mathrm{~h}$, seguindo método preconizado pela Embrapa (1997). O pH foi definido potenciometricamente usando a relação $1: 2,5$ de solo em $\mathrm{CaCl}_{2}$ 0,01 $\mathrm{mol} \mathrm{L}^{-1}$. Cálcio, $\mathrm{Mg}$ e $\mathrm{K}$ trocáveis e o $\mathrm{P}$ disponível foram extraídos pelo método da resina trocadora de íons. A matéria orgânica foi determinada pelo método colorimétrico por dicromato de sódio a $0,1 \mathrm{~mol} \mathrm{~L}^{-1}$; e a acidez potencial, conforme Raij et al. (2001). Foram calculadas as somas de bases, a capacidade de troca catiônica e a saturação por bases.

O valor da Suscetibilidade magnética (SM) "X" foi avaliado em laboratório, para todas as amostras coletadas, utilizando-se de uma balança analítica de acordo com método de Carneiro et al. (2003), Cano et al. (2008) e adaptada para leitura da SM do solo por Siqueira et al. (2010b). O aparato é constituído de uma balança analítica, um imã, suporte para o imã e porta-amostra. A interação dos minerais com expressão magnética, presentes na amostra de solo, com o imã, gera na balança uma força peso. Essa força peso é então convertida em SM utilizando uma curva-padrão.

Os resultados dos atributos químicos e granulométricos e da SM das amostras nas diferentes SGs foram submetidos à análise de comparações das médias, pelo teste de Tukey $(p<0,05)$ e análise de variância multivariada, utilizando o programa SAS (SAS, 2007) e o
Statistica versão 12 . Dessa maneira, para a aplicação do teste de Tukey, cada ponto coletado em cada área foi interpretado como sendo uma pseudorrepetição. O teste de Tukey leva em conta o desbalanceamento dessas pseudorrepetições.

Para validar os limites dos compartimentos da paisagem identificados no campo, com base nos modelos de superfície geomórfica e nos segmentos de vertentes, foi realizada a análise Split Moving Windows Dissimilarity Analysis (SMWDA), conforme descrito por Webster (1978). Essa análise é com base em cálculos estatísticos de dissimilaridades entre sequências de grupos de pontos amostrais coletados em sequência na transeção. Com esses, é possível identificar com precisão os limites entre áreas com diferentes padrões de homogeneidade dos atributos do solo (Webster, 1978). Primeiramente, é escolhido um conjunto com " $\mathrm{n}$ " pontos, denominado "Janela". Essa janela é então "movimentada" consecutivamente do início da transeção até o fim da transeção, ponto a ponto. Em cada nova posição da transeção, a janela é dividida em duas partes ou duas janelas, sendo calculadas e comparadas as médias das duas janelas. Essas comparações de médias são feitas usando-se o teste $t$-Student. $\mathrm{O}$ valor desses testes é colocado em um gráfico (valor do teste $t$-Student versus distância). Picos maiores nesse gráfico correspondem então aos valores de $t$-Student mais elevados e identificam limites matemáticos entre áreas com diferentes variações dos atributos do solo.

O comprimento da Janela pode ser determinado pela análise de autocorrelação, utilizando os atributos originais (Webster, 1973, 1978), e pelo índice de Mullion (Berg, 1988), que consiste na distância prefixada entre as duas partes da "Janela". No gráfico gerado, os maiores picos correspondem a valores mais elevados da estatística $t$, que indicam os limites matemáticos entre áreas com diferentes variações dos atributos do solo.

O cálculo da estatística t é dado pela equação 1 :

$$
t=\frac{\bar{x}_{1}-\bar{x}_{2}}{S_{p} \sqrt{\frac{1}{n_{1}}+\frac{1}{n_{2}}}},
$$

Eq. 1

em que $\bar{x}_{1}$ e $\bar{x}_{2}$ são as médias amostrais das duas "Janela" $\left(\mathrm{n}_{1}\right.$ e $\left.\mathrm{n}_{2}\right)$ e Sp é a estimativa combinada do desvio-padrão comum, dado pela equação 2 :

$$
S_{p}=\frac{\left(n_{1}-1\right) S_{1}+\left(n_{2}-1\right) S_{2}}{n_{1}+n_{2}-2},
$$

em que $\mathrm{S}_{1}$ e $\mathrm{S}_{2}$ são os desvios-padrão e $\mathrm{n}_{1}$ e $\mathrm{n}_{2}$ os tamanhos amostrais das duas "Janela" previamente estabelecidas. Neste estudo, foram utilizadas "Janela" de 16 observações e Mullion de duas observações.

Também foi realizada a análise de agrupamento hierárquico (Sneath e Sokal, 1973). O objetivo dessa análise foi verificar quais amostras de solo possuíam semelhança quanto às características 
granulométricas, químicas e suscetibilidade magnética, capaz de dividir a área nas três superfícies geomórficas, por meio da análise de variância $(p<0,05)$ e dendograma. Os coeficientes de dissimilaridade foram calculados a partir da distância euclidiana. Os agrupamentos foram feitos utilizando o algoritmo de ligação completa (Hair et al., 2005). Nesse método, o pesquisador estabelece o nível do agrupamento de acordo com um critério de fácil compreensão.

O critério de agrupamento selecionado foi o da distância média entre grupos (average linkage between groups), segundo o qual a distância entre dois grupos (ou clusters) é igual à distância média entre todos os pares possíveis de elementos dos dois grupos; em cada par, um elemento pertence a uma categoria e o outro à outra. Esse é também um dos procedimentos mais utilizado e conta com a vantagem de usar a informação sobre todos os elementos disponíveis na hora de decidir o agrupamento, ou seja, sobre todos os pares de distâncias. As categorias mais próximas segundo esse critério serão aquelas integradas em uma só no passo seguinte. Esse procedimento procura maximizar as diferenças entre grupos, enquanto outros tentam diminuir as diferenças dentro de cada grupo (Scalon, 1998).

A medida da distância determinará o modo como se calculará a matriz de proximidade entre todos os elementos. Nesse caso, optou-se pela distância euclidiana ao quadrado, uma das mais usadas na literatura. Essa distância é calculada do seguinte modo: subtraindo-se o valor dos dois elementos para cada dimensão e elevando-o ao quadrado. A soma de todos esses quadrados, tantos quantas dimensões sejam usadas na classificação, é igual à distância entre os dois elementos. Essa medida penaliza fortemente as distâncias mais longas em relação às mais próximas (Scalon, 1998), descrita pela equação 3 :

Distância $(\mathrm{X}, \mathrm{Y})=\sum\left(\mathrm{X}_{\mathrm{i}}-\mathrm{Y}_{\mathrm{i}}\right)^{2}$

Eq. 3

Assim, a distância entre dois casos é medida pela soma das diferenças entre os valores de cada variável elevada ao quadrado.

No estudo, foram usados métodos aglomerativos, que representam um processo de fusão dos elementos em novos grupos. Seu procedimento básico é sequencial, aglomerativo, hierárquico e não sobreposto (nonoverlaping). O processo começa com a computação de uma distância ou uma matriz de similaridade entre os $1 / 2(\mathrm{~N})(\mathrm{N} 1)$ pares possíveis de elementos. Uma vez que os índices estão disponíveis, a matriz é examinada com a finalidade de encontrar o par i e j mais próximo ou mais similar. Assim, i e j são fundidos para formar o cluster $\mathrm{k}$, e a matriz de entrada de valores é modificada para refletir a mudança. A matriz é examinada novamente na busca de par mais próximo, e os dois são fundidos em um novo cluster. O processo segue até todos os elementos estarem em um mesmo cluster (Goldthorpe, 1983).

\section{RESULTADOS E DISCUSSÃO}

Observa-se, no quadro 1, que os valores dos atributos químicos $\mathrm{pH}\left(\mathrm{CaCl}_{2}\right), \mathrm{P}, \mathrm{Ca}^{2+}$, soma de bases (SB), capacidade de troca de cátions (CTC) e saturação por bases (V), na profundidade de 0,00-0,20 m, não diferiram estatisticamente entre as superfícies geomórficas II e III (SG II e SG III). Isso indica tendência de maior variabilidade, decorrente da lixiviação dos nutrientes oriundos dos locais mais altos (SG I) para os mais baixos (SG II e SG III). Matias et al. (2013), estudando o comportamento de vertentes, observaram esse mesmo resultado, confirmando a teoria de Ruhe (1969) e Daniels et al. (1971).

Porém, registram-se diferenças estatísticas dos atributos $\mathrm{P}, \mathrm{Ca}^{2+}, \mathrm{SB}, \mathrm{CTC}$ e V em comparação com a SG I. Essa diferenciação, provavelmente, deve-se ao efeito de manejo do solo (aplicação de adubos), no longo dos anos, relevo, escoamento superficial dos nutrientes, cobertura do solo, baixa mobilidade dos nutrientes e falta de homogeneidade das aplicações, levando ao desbalanceamento dos nutrientes em determinados locais. Sanchez et al. (2012) descreveram em seus estudos que a falta do planejamento das áreas agrícolas principalmente no que se refere à aplicação de insumos agrícolas (adubos) acarreta sérios prejuízos para o produtor, refletindo na variação da produção, consequentemente, apresentando prejuízos de ordem econômica. Além disso, Matias et al. (2013) destacaram que mesmo em solos classificados taxonomicamente iguais a posição da paisagem deve ser considerada para melhor entendimento da causa efeito na produção, indicando a forma de manejo correto, refletindo na diminuindo dos gastos com insumos agrícolas. Sousa et al. (2012), estudando o efeito da cobertura em diferentes vertentes, concluíram que a cobertura do solo e o relevo interferem no comportamento do nutriente (deslocamento), provocado pelo escoamento superficial (erosão).

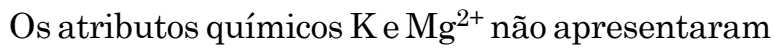
diferença significativa entre as superfícies geomórficas nas duas profundidades. $\mathrm{O}$ único atributo químico que evidenciou diferença significativa entre as três superfícies, na profundidade de 0,00-0,20 m, foi a matéria orgânica (MO), o que provavelmente é reflexo do manejo, indicando que a cobertura vegetal (raleada) está sendo decomposta e incorporada no solo de forma rápida.

$\mathrm{Na}$ profundidade de $0,60-0,80 \mathrm{~m}$, os atributos $\mathrm{MO}$, acidez potencial $(\mathrm{H}+\mathrm{Al})$ e CTC evidenciaram 
Quadro 1. Atributos químicos, granulométricos e suscetibilidade magnética nas profundidades de 0,00-0,20 e 0,60-0,80 m, nas superfícies geomórficas I, II e III

\begin{tabular}{|c|c|c|c|c|c|c|c|c|c|c|c|c|c|}
\hline Superfície geomórfica & $\mathrm{pH}\left(\mathrm{CaCl}_{2}\right)$ & MO & $\mathbf{P}$ & $\mathbf{K}^{+}$ & $\mathrm{Ca}^{2+}$ & $\mathrm{Mg}^{2+}$ & $\mathbf{H}+\mathbf{A l}$ & SB & CTC & V & AT & Arg & SM \\
\hline & & $\mathrm{g} \mathrm{dm}^{-3}$ & $\mathrm{mg} \mathrm{dm} \mathrm{m}^{-3}$ & \multicolumn{6}{|c|}{$\mathrm{mmol}_{\mathrm{c}} \mathrm{dm}^{-3}$} & $\%$ & $\mathrm{~g} \mathrm{k}$ & $\mathrm{rg}^{-1}$ & $10^{-6} \mathrm{~m}^{3} \mathrm{~kg}^{-1}$ \\
\hline & \multicolumn{13}{|c|}{$0,00-0,20 \mathrm{~m}$} \\
\hline SG I & $5,5 \mathrm{a}$ & $17,7 \mathrm{c}$ & $38,9 \mathrm{a}$ & $2,1 \mathrm{a}$ & $48,2 \mathrm{a}$ & $11,7 \mathrm{a}$ & $24,7 \mathrm{~b}$ & $62,2 \mathrm{a}$ & 86,9 a & $66 \mathrm{a}$ & $587 \mathrm{~b}$ & $372 \mathrm{~b}$ & $2,7 \mathrm{c}$ \\
\hline SG II & $5,0 \mathrm{~b}$ & $21,4 \mathrm{~b}$ & $16,9 \mathrm{~b}$ & $3,2 \mathrm{a}$ & $20,2 \mathrm{~b}$ & $12,1 \mathrm{a}$ & $30,7 \mathrm{ab}$ & $35,6 \mathrm{~b}$ & $66,4 \mathrm{~b}$ & $52 \mathrm{~b}$ & $629 \mathrm{a}$ & $338 \mathrm{c}$ & $3,9 \mathrm{~b}$ \\
\hline SG III & \multicolumn{12}{|c|}{$0,60-0,80 \mathrm{~m}$} & 7,1 a \\
\hline SG I & $4,1 \mathrm{~b}$ & $11,2 \mathrm{a}$ & $6,1 \mathrm{a}$ & $0,8 \mathrm{a}$ & $9,7 \mathrm{a}$ & $3,2 \mathrm{a}$ & $44,6 \mathrm{a}$ & $13,8 \mathrm{a}$ & $58,4 \mathrm{a}$ & $22 \mathrm{a}$ & $536 \mathrm{a}$ & $429 \mathrm{~b}$ & $2,3 \mathrm{c}$ \\
\hline SG II & $4,3 \mathrm{ab}$ & $8,4 \mathrm{~b}$ & $10,1 \mathrm{a}$ & $0,8 \mathrm{a}$ & $7,2 \mathrm{a}$ & $3,2 \mathrm{a}$ & $35,5 \mathrm{~b}$ & $11,3 \mathrm{a}$ & $46,8 \mathrm{~b}$ & $26 \mathrm{a}$ & $553 \mathrm{a}$ & $417 \mathrm{~b}$ & $3,9 \mathrm{~b}$ \\
\hline SG III & $4,5 \mathrm{a}$ & $9,3 \mathrm{~b}$ & $7,9 \mathrm{a}$ & $0,5 \mathrm{a}$ & $10,7 \mathrm{a}$ & $3,9 \mathrm{a}$ & $32,8 \mathrm{~b}$ & $15,2 \mathrm{a}$ & $48,0 \mathrm{~b}$ & $32 \mathrm{a}$ & $458 \mathrm{~b}$ & $506 \mathrm{a}$ & $6,6 \mathrm{a}$ \\
\hline
\end{tabular}

Letras iguais na mesma coluna não diferem estatisticamente pelo teste de Tukey $(\mathrm{p}<0,05)$. $\mathrm{pH}$ medido em solução de $\mathrm{CaCl}_{2} 0.01 \mathrm{~mol} \mathrm{~L}^{-1}$;

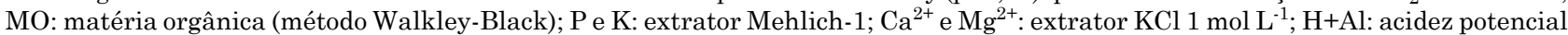
(extrator acetato de cálcio 0,5 mol L-1 $\mathrm{pH}$ 7); SB: soma de bases; CTC: capacidade de troca catiônica; V: saturação por bases; AT: areia total, e Arg: argila (método da pipeta); e SM: suscetibilidade magnética.

diferença significativa entre as SG I e SG II e o pH entre as SG I e SG III, esse comportamento confirma a baixa mobilidade do Ca (correção de acidez) das camadas superficiais para as mais profundas e também a lixiviação dos nutrientes.

Estudando a paisagem e seu reflexo nos atributos químicos do solo, Campos et al. (2012b) observaram diferenciação da SG I para SG II e III no pH, MO, $\mathrm{Ca}, \mathrm{Mg}, \mathrm{H}+\mathrm{Al}$; Meireles et al. (2012) observaram diferenciação entre MO, SB, CTC e V, entre as SG I, II e III. Os autores concluíram que a posição da paisagem (relevo) deve ser levada em conta no manejo (cobertura e adubo), mesmo em áreas consideradas planas.

Já a areia total (AT) e argila (Arg) demonstraram diferença em relação às três superfícies geomórficas identificadas no campo na profundidade de 0,00-0,20 m. Porém, o mesmo não foi observado na profundidade de 0,60-0,80 m (Quadro 1). Esses resultados indicam que a retirada da cultura e implantação de novas, que implica no revolvimento do solo e consequentemente na exposição do solo aos intemperes climáticos (chuva e vento), pode acelerar o processo de erosão em curto período. Dessa forma, promove o deslocamento de partículas do solo mais leve como a argila para outros locais, ocorrendo a deposição, em comparação à da areia. Sousa et al. (2012), ao analisarem o efeito de coberturas no solo, considerando a posição da paisagem, observaram resultados semelhantes, indicando que o manejo deve ser reflexo do relevo, mesmo em áreas consideradas praticamente planas.

Trabalhos como os de Campos et al. (2012a,b), Meireles et al. (2012) e Matias et al. (2013), vêm observando comportamento semelhante (deposição das partículas da argila e areia decorrente do relevo) nos atributos granulométricos em estudos de paisagem, permitindo identificar locais com maior ou menor variabilidade espacial e, também, distinção de áreas consideradas homogêneas. Os autores ainda descreveram que os atributos granulométricos são reflexo direto das condições edafoclimáticas da região e do material de origem. Além disso, Souza Junior et al. (2010) descreveram que a quantificação da granulometria do solo permite distinguir qual o mineral ferrimagnético, como a magnetita (fração areia) e a maghemita (fração argila), está interferindo nos valores da SM. O aumento da $\mathrm{SM}$ da SGI $\left(\sim 5 \% \mathrm{Fe}_{2} \mathrm{O}_{3}\right)$ para SGIII $\left(\sim 10 \% \mathrm{Fe}_{2} \mathrm{O}_{3}\right)$ pode estar relacionado ao aumento de minerais litogenéticos como a magnetita. Os menores valores de SM na SGI possivelmente estão associados à presença de minerais pedogenéticos como maghemita e ferridrita ferrimagnética (Torrent et al., 2006).

Diante do exposto, observou-se que os valores de SM (Quadro 1) apresentaram-se crescentes e significativos no sentido I $>$ II $>$ III, nas duas profundidades, confirmando a teoria de Ruhe (1969) e Daniels et al. (1971), em que descrevem que a paisagem reflete a idade do solo, ou seja, quanto mais próximo da rocha ou menos intemperizado for o solo, maiores serão os valores dos atributos do solo (químico e mineralógico). Conduzindo um estudo sobre SM na delimitação e identificação de paisagem e sua relação com o solo, Zawadzki et al. (2012) e Matias et al. (2013) concluíram que a susceptibilidade magnética demonstrou ter potencial para discriminar as superfícies geomórficas mapeadas no campo e sua relação com o perfil, demonstrando que é possível integrar as medidas da SM com o solo, indicando o seu potencial de uso na identificação e caracterização de áreas mais homogêneas e nos ambientes semelhantes. 
Ressalta-se que este estudo foi realizado em um solo com a mesma classificação taxonômica, com teores de óxidos de Fe variando de 48,1 a $96,2 \mathrm{~g} \mathrm{~kg}^{-1}$ da SG I para SG II (Matias et al., 2013), com diferença basicamente no relevo e no nível de subordens (Vermelho) na SG III, relacionada provavelmente com a presença de hematita e minerais ferrimagnéticos. Essas observações confirmaram os resultados de Matias et al. (2013), os quais também observaram variações na SM ao longo de uma topossequência. Essas variações foram relacionadas com as diferenças na composição da paisagem e a influência de fatores de formação, mineralogia e erosão do solo, que são condicionados pela forma da paisagem (Torrent et al., 2010; Sousa et al., 2012). Souza Junior et al. (2010) observaram uma estreita relação da SM com os minerais que possuem expressão magnética, principalmente os óxidos de $\mathrm{Fe}$, que são os minerais de maior ocorrência nos solos tropicais altamente intemperizados, como os Latossolos.

$\mathrm{O}$ resultado da $\mathrm{SM}$ evidencia que esse atributo foi o que apresentou melhor potencial de uso para validar os compartimentos da paisagem identificados no campo (Quadro 1). Porém, segundo Campos et al. (2012a), Zawadzki et al. (2012) e Matias et al. (2013), esse tipo de interpretação feita somente com base nos resultados da análise univariada pode causar falsas impressões, dificultando ainda mais a compreensão da relação pedologia-geomorfologia.

Nesse sentido, frente à pouca eficiência da análise univariada para discriminar as superfícies geomórficas, utilizou-se a técnica de análise multivariada nos atributos químicos e granulométricos do solo, procurando caracterizar esses compartimentos de forma conjunta. Ressalta-se que a não utilização da variável SM nessa análise é reflexo da teoria da multivariada, ou seja, fazer análise a partir de um grupo de variáveis.
Os resultados da análise de variância multivariada para os atributos químicos apresentaram diferença significativa $(p<0,0001)$ entre as superfícies geomórficas para todos os contrastes testados, em ambas as profundidades (Quadro 2), o que confirma o mapeamento das superfícies realizadas no campo. Barris et al. (2012), estudando a relação solo-paisagem por meio de análise de variância multivariada, associada à análise de componentes principais, concluíram que esse tipo de análise permitiu discriminar duas áreas em uma área de transição de arenito-basalto, podendo ser utilizada como técnica auxiliar em estudos de variabilidade espacial. Campos et al. (2012b) e Meireles et al. (2012) verificaram que a técnica da estatística multivariada permitiu discriminar três superfícies geomórficas em uma litossequência de arenito-basalto e topossequência de basalto. Os autores ainda descreveram que a análise multivariada foi eficiente para discriminar solos agrícolas manejados com diferentes sistemas por meio dos atributos químicos (Barris et al., 2012).

Os atributos granulométricos apresentaram diferença significativa entre as SG I, SG II e SG III $(p<0,0001)$, nas duas profundidades, com exceção apenas para o contraste SG I vs II em 0,60-0,80 m (Quadro 2). Isso indica que em maiores profundidades a SG I e SG II podem ser consideradas como um mesmo compartimento. Esse conhecimento é importante, pois auxilia no melhor planejamento das práticas de manejo em áreas homogêneas, tanto em superfície como em subsuperfície (Sanchez et al., 2012). Segundo Campos et al. (2012b), Barris et al. (2012) e Meireles et al. (2012), o uso da combinação de variáveis independentes, por meio de técnicas multivariadas, permite discriminação de grupos, de maneira que os erros na classificação sejam minimizados. Assim, podem-se fornecer informações importantes para interpretação correta do

Quadro 2. Valores da análise multivariada dos atributos químicos e granulométricos nas profundidades de 0,00-0,20 e 0,60-0,80 m, nas superfícies geomórficas I, II e III

\begin{tabular}{|c|c|c|c|c|c|c|c|c|}
\hline \multirow[b]{2}{*}{ Contraste } & \multicolumn{4}{|c|}{ Atributo químico } & \multicolumn{4}{|c|}{ Atributo granulométrico } \\
\hline & Wilks & $\begin{array}{l}\text { Pillai's } \\
\text { trace test }\end{array}$ & $\begin{array}{c}\text { Hotelling Lawley's } \\
\text { race test }\end{array}$ & $\begin{array}{c}\text { Roy's } \\
\text { Maximum Root }\end{array}$ & Wilks & $\begin{array}{c}\text { Pillai's } \\
\text { trace test }\end{array}$ & $\begin{array}{c}\text { Hotelling Lawley's } \\
\text { race test }\end{array}$ & $\begin{array}{c}\text { Roy's } \\
\text { Maximum Root }\end{array}$ \\
\hline & \multicolumn{8}{|c|}{$0,00-0,20 \mathrm{~m}$} \\
\hline SG I vs II & $<0,0001$ & $<0,0001$ & $<0,0001$ & $<0,0001$ & 0,0013 & 0,0013 & 0,0013 & 0,0013 \\
\hline SG I vs III & $<0,0001$ & $<0,0001$ & $<0,0001$ & $<0,0001$ & $<0,0001$ & $<0,0001$ & $<0,0001$ & $<0,0001$ \\
\hline SG II vs III & $<0,0001$ & $<0,0001$ & $<0,0001$ & $<0,0001$ & $<0,0001$ & $<0,0001$ & $<0,0001$ & $<0,0001$ \\
\hline \multirow[t]{2}{*}{ SG I vs II vs III } & $<0,0001$ & $<0,0001$ & $<0,0001$ & $<0,0001$ & $<0,0001$ & $<0,0001$ & $<0,0001$ & $<0,0001$ \\
\hline & \multicolumn{8}{|c|}{$0,60-0,80 \mathrm{~m}$} \\
\hline SG I vs II & $<0,0001$ & $<0,0001$ & $<0,0001$ & $<0,0001$ & $0,2887^{\text {ns }}$ & $0,2887^{\mathrm{ns}}$ & $0,2887^{\mathrm{ns}}$ & $0,2887^{\mathrm{ns}}$ \\
\hline SG I vs III & $<0,0001$ & $<0,0001$ & $<0,0001$ & $<0,0001$ & $<0,0001$ & $<0,0001$ & $<0,0001$ & $<0,0001$ \\
\hline SG II vs III & $<0,0001$ & $<0,0001$ & $<0,0001$ & $<0,0001$ & $<0,0001$ & $<0,0001$ & $<0,0001$ & $<0,0001$ \\
\hline SG I vs II vs III & $<0,0001$ & $<0,0001$ & $<0,0001$ & $<0,0001$ & $<0,0001$ & $<0,0001$ & $<0,0001$ & $<0,0001$ \\
\hline
\end{tabular}

SG I, II e III: superfície geomórfica I, II e III. Nível de significância (p<0,01); ${ }^{\text {ns: }}$ não significativo. 
planejamento da capacidade de uso do solo, entendimento da paisagem, comportamento dos atributos do solo, bem como a sua distribuição espacial, já que se estabelecem relações entre a topografia e os atributos (Campos et al., 2012b).

Com base nos resultados da análise univariada (Quadro 1) e multivariada (Quadro 2), pode-se sugerir que a SM tem potencial na identificação de áreas com diferentes padrões de homogeneidade e sua utilização pelos mapeadores pode melhorar a precisão dos limites entre áreas mapeadas, já que a SM permitiu identificar as três superfícies, da mesma forma que foram identificadas na multivariada pelos atributos químicos. Nesse caso, a identificação desses limites se torna ainda mais difícil de ser realizada com precisão em regiões de transição de material de origem; como exemplo, a transição arenito-basalto, que segundo o mapa do IPT (1981) ocupa aproximadamente 3,5 \% do Estado de São Paulo (aproximadamente $873,5 \mathrm{mil}$ ha), que coincidem com os principais polos sucroenergéticos do país. Isso denota a importância no desenvolvimento de ferramentas que auxiliem na melhor compreensão dos limites entre áreas distintas, visando à adoção de estratégias de uso e manejo mais conservacionistas. Nesses locais, muitas vezes a interpretação da homogeneidade do solo é com base em sua cor, gerando conclusões equivocadas. Isso interfere nos estudos de causa e efeito sobre a resposta das culturas agrícolas e o ambiente em que estão inseridas (Sanchez et al., 2012).

Os resultados da análise de autocorrelograma pela técnica do SMWDA para os atributos altitude, granulometria, químicos e SM das amostras coletadas na transeção nas duas profundidades em estudo são apresentados na figura 2. A aplicação do SMWDA, para os valores de altitude, permitiu visualizar os limites das superfícies geomórficas e os segmentos de vertentes. Observa-se que os maiores picos dos valores de $t$-Student estão próximo com a transição entre as SG I, SG II e SG III, respectivamente a 500 e $1.400 \mathrm{~m}$. Os outros picos intermediários a 800 e 1.200 m identificam limites entre os segmentos de vertentes (Figuras 1 e 2). Esse resultado confirma que as técnicas (modelos de paisagem e vertentes) empregadas por Dalrymple et al. (1968) e Daniels et al. (1971) são fortemente baseadas nas quebras do relevo e pequenas variações da declividade.

Para os atributos químicos (pH, P, SB e CTC), foi verificado o mesmo resultado do quadro 1 , ou seja, mesmo sendo utilizadas técnicas matemáticas diferentes, o resultado provavelmente serão os mesmos para alguns atributos químicos. Os demais atributos químicos estudados não permitiram a separação das superfícies geomórficas e vertentes, por isso não foram representados na figura 2 . Espinar et al. (2011) e Erdős et al. (2013), ao separarem uma área por meio dos atributos químicos, verificaram que o manejo e o material de origem podem interferir no resultado em virtude de serem atributos facilmente manejado.

Esse resultado também foi semelhante ao obtidos por Campos et al. (2012a,b) e Matias et al. (2013), os quais verificaram em seus estudos que os atributos químicos quando analisados por meio da estatística univariada e seus semelhantes, como a SMWDA, que tem como base a teoria da análise $t$-Student, não são eficientes em discriminar ou separar as superfícies de forma clara e precisa, situação essa atribuída à falta de conhecimento de estudos sobre essa técnica, o tamanho da janela (Erdôs et al., 2011, 2012) e a pouca variação existente entre as áreas. A proposta de dividir a paisagem por meio do SMWDA é antiga; segundo Erdős et al. (2011), Ross e Sah (2011), Espinar et al. (2011), Xu et al. (2012) e Erdós et al. (2013), a sua maior desvantagem está na falta de capacidade de analisar limites em escalas diferentes e janelas, levando na sua maioria a reprodução dos tamanhos de janelas predefinida.

Os picos do $t$-Student obtidos para AT e ARG estão próximos dos limites estabelecidos no campo para as superfícies geomórficas, com exceção da SG I, respectivamente 600 e $820 \mathrm{~m}$ para as profundidades 0,00-0,20 e 0,60-0,80 m. Os limites estabelecidos no campo para as vertentes, ombro e a meia encosta na SG III a $1.800 \mathrm{~m}$ e entre a meia encosta e o sopé, a $2.200 \mathrm{~m}$, estão bastante evidenciados para ambas as profundidades (Figuras 1 e 2), confirmando a divisão feita no campo. Utilizando a técnica do SMWDA em uma transeção, Cunha et al. (2005) observaram que os atributos granulométricos foram os que mais coincidiram com os limites predefinidos das superfícies geomórficas delimitadas no campo. Ross e Sah (2011) e Espinar et al. (2011) verificaram que os atributos físicos têm estreita relação com a paisagem. Erdôs et al. (2011), Xu et al. (2012) e Erdôs et al. (2013) observaram resultados semelhantes em seus estudos em uma paisagem, confirmando que essa técnica é bastante segura, podendo ser utilizada para auxiliar na discriminação dos limites de processos pedogeomórficos e ambientais.

A proximidade dos limites de campo, com os picos da análise $t$-Student, indica que os modelos propostos por Dalrymple et al. (1968) e Daniels et al. (1971) podem ser utilizados de forma prática como ferramenta auxiliar na identificação dos limites entre áreas com diferentes padrões de variação e por conseguinte auxiliar nos levantamentos pedológicos detalhados ou no mapeamento de áreas de manejo específico.

Os picos mais evidentes em ambas as profundidades foram observados para SM por meio do SMWDA. Isso indica que os limites das áreas com diferentes padrões de homogeneidade identificados com base nos valores da SM pela técnica do SMWDA coincidiram com os limites identificados no campo, utilizando como base os modelos de paisagem. Assim, a divisão de uma área em superfícies geomórficas 
Altitude

$\begin{array}{lllll}400 \quad 800 & 1.200 & 1.6001 .800 & 2.200\end{array}$

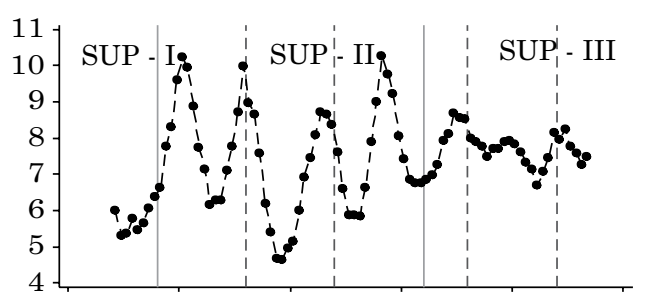

Argila

$400 \quad 800 \quad 1.2001 .6001 .800 \quad 2.200$

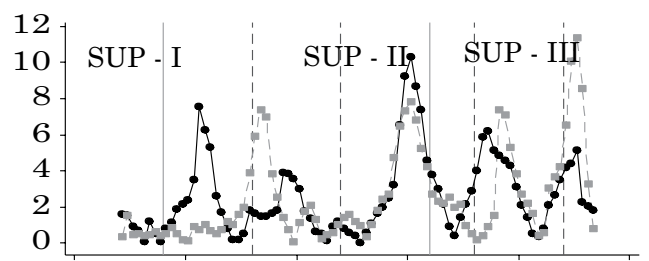

Fósforo

$400 \quad 800 \quad 1.2001 .6001 .8002 .200$

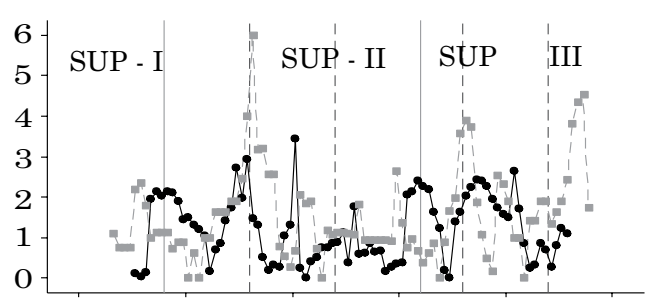

CTC

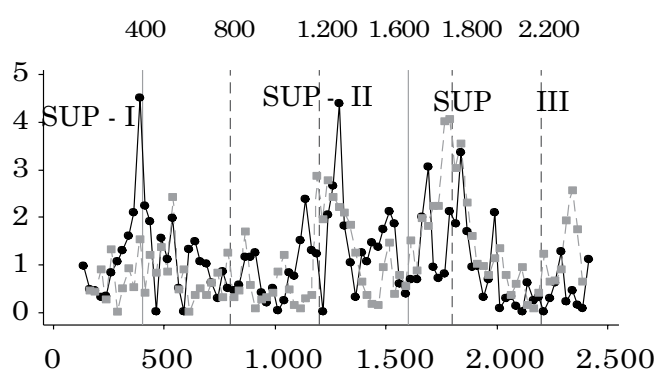

Areia Total

$\begin{array}{llllll}400 \quad 800 \quad 1.200 & 1.600 & 1.800 & 2.200\end{array}$

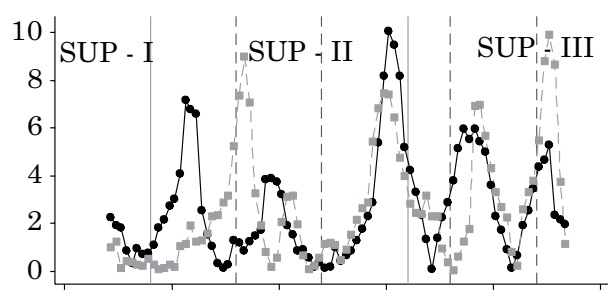

$\mathrm{pH}\left(\mathrm{CaCl}_{2}\right)$

$400 \quad 800 \quad 1.200 \quad 1.600 \quad 1.800 \quad 2.200$

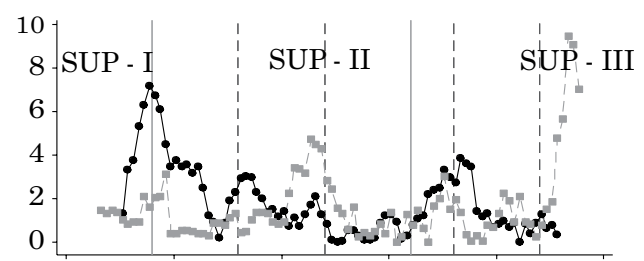

Soma de Bases

$\begin{array}{lllll}400 \quad 800 & 1.200 & 1.600 & 1.800 & 2.200\end{array}$

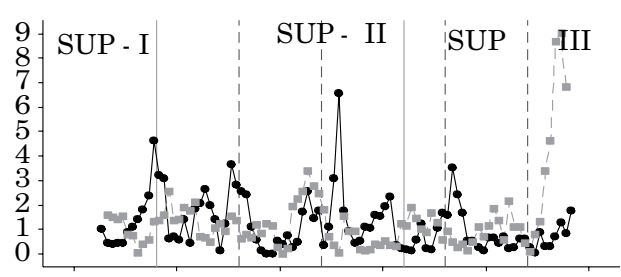

Suscetibilidade Magnética

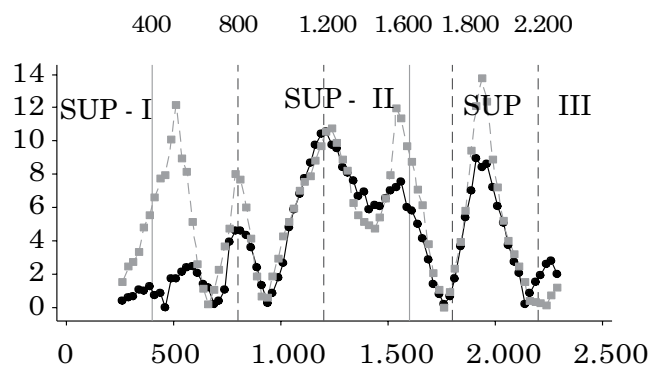

Distância na transeção (m)

Figura 2. Valores da Split Moving Windows Dissimilarity Analysis (SMWDA), "Janelas Móveis", dos atributos do solo, em uma transeção. Os "picos" mais elevados indicam locais de mudanças mais notáveis da inclinação do terreno (nick points). Os picos pretos, com linha contínua, e os cinzas, com linha pontilhada, representam as profundidades de $0,00-0,20$ e $0,60-0,80 \mathrm{~m}$, respectivamente, com exceção da altitude. A linha contínua cinza separa as superfícies geomórficas e, as tracejadas, os segmentos de vertentes. 


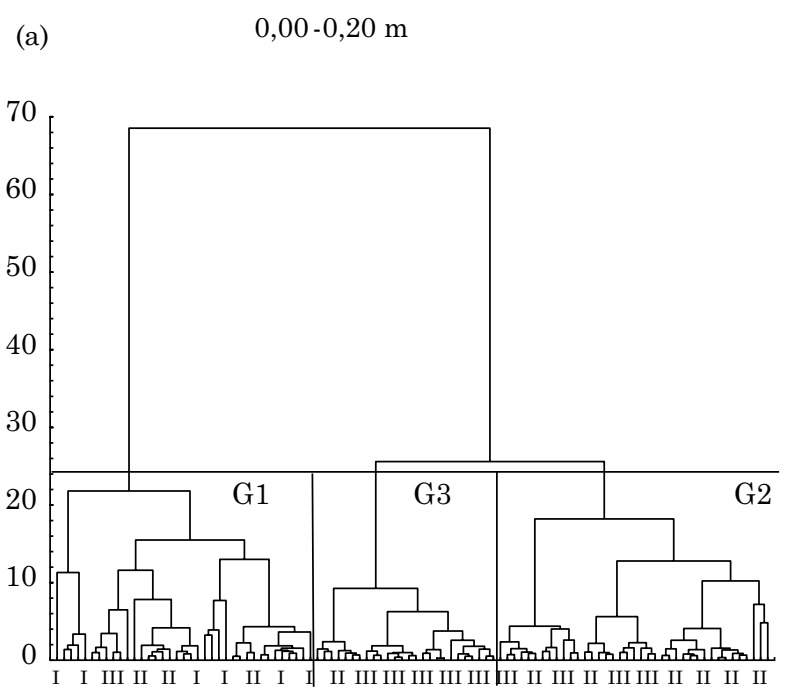

(b)

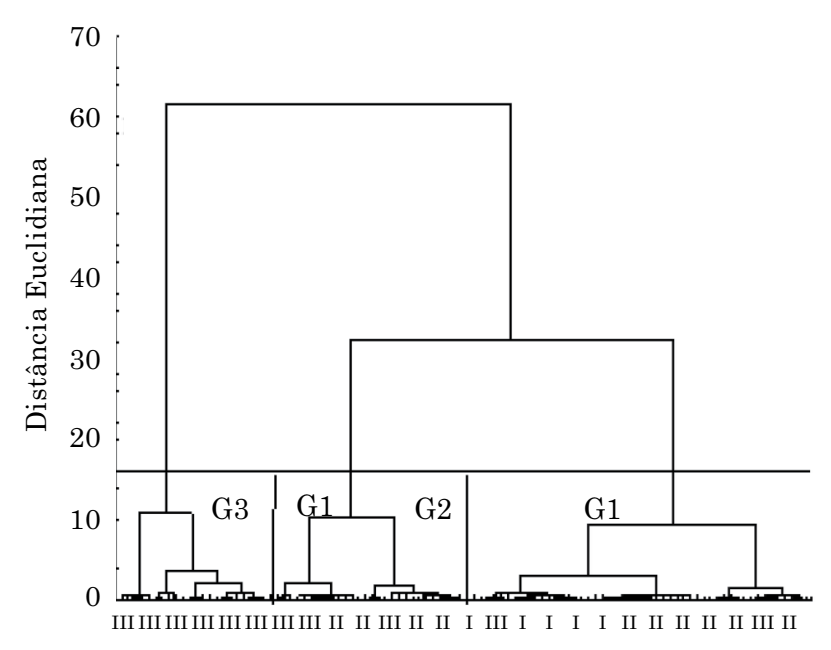

(c)

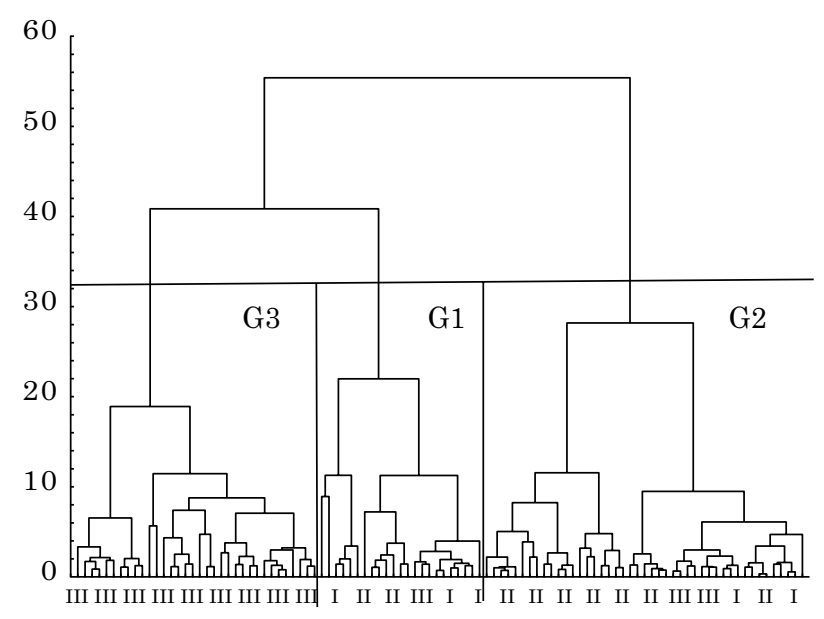

(d)

$0,60-0,80 \mathrm{~m}$

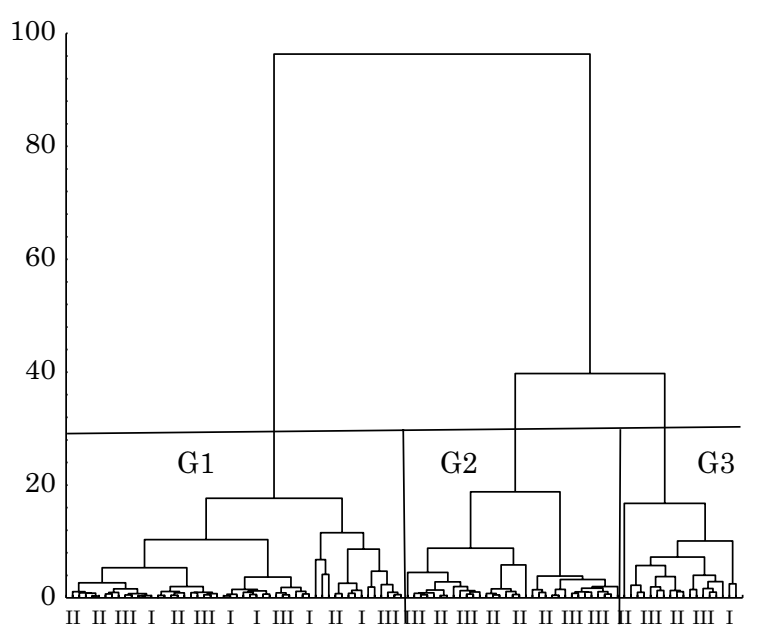

(e)

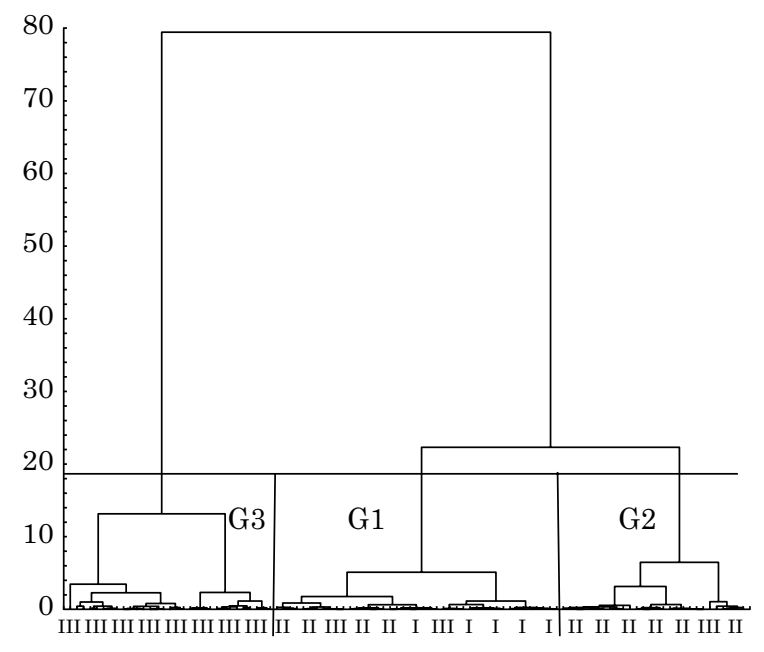

(f)

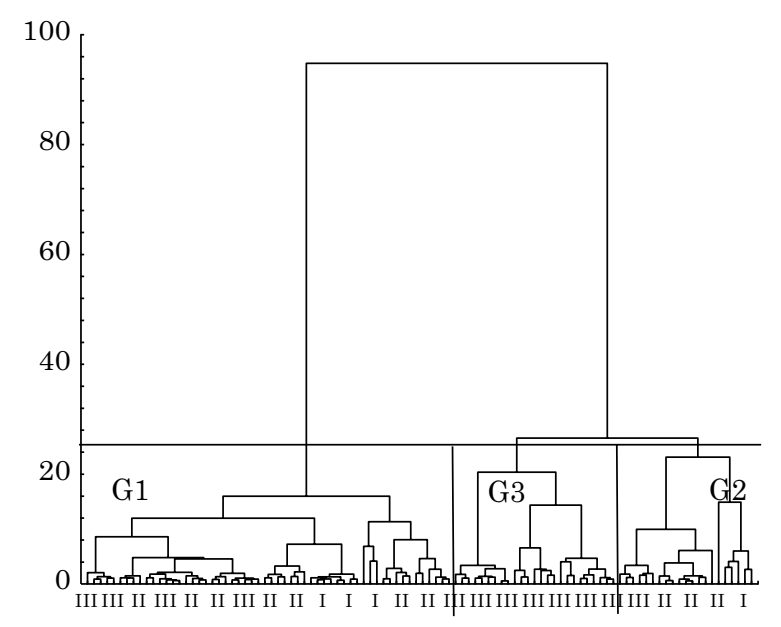

Figura 3. Análise de agrupamento (dendograma) dos atributos químicos, granulométricos e sua relação em duas profundidades $(0,00-0,20$ e 0,60-0,80 m), em uma transeção, na separação das superfícies geomórficas. Separação das superfícies por meio dos atributos químicos (a, d), granulométricos (b, e) e químico e granulométricos (c, f). 
(a)

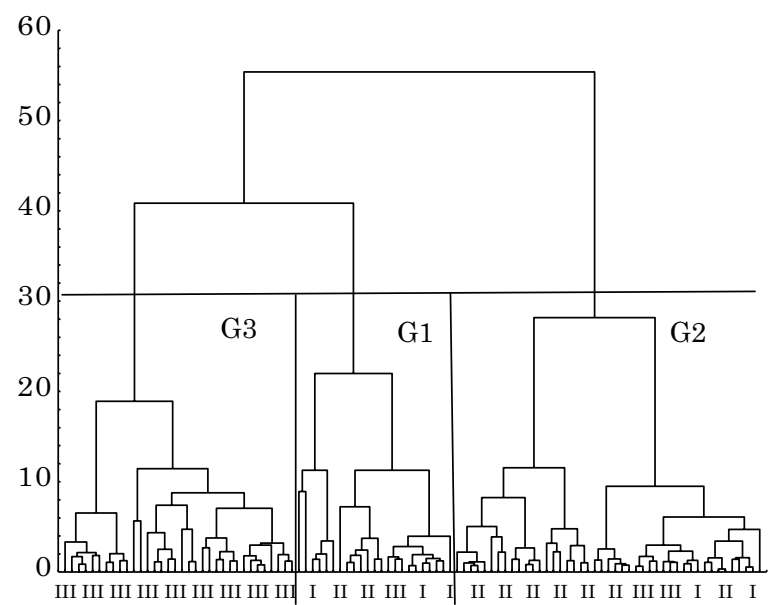

(b)

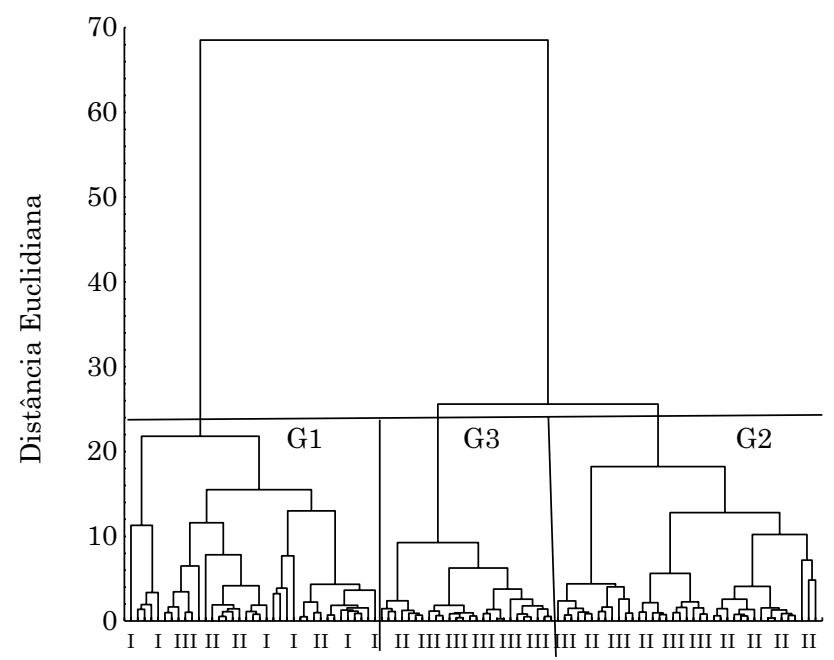

(c)

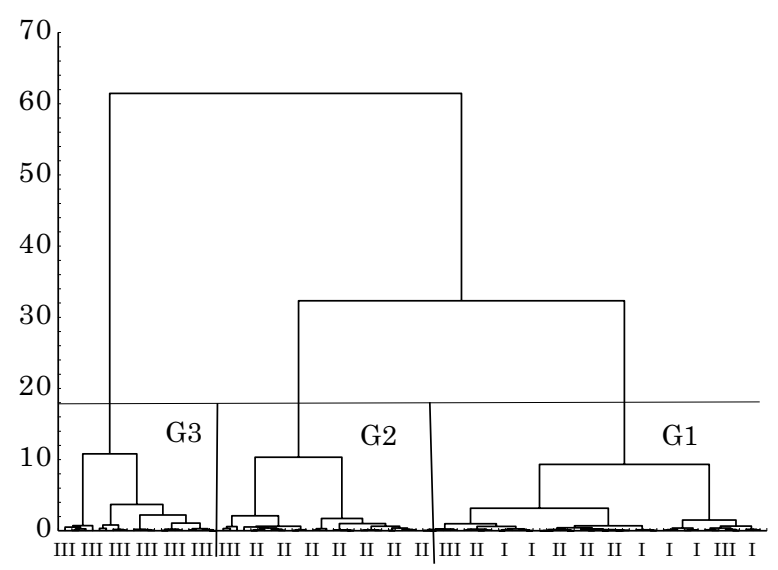

(d)

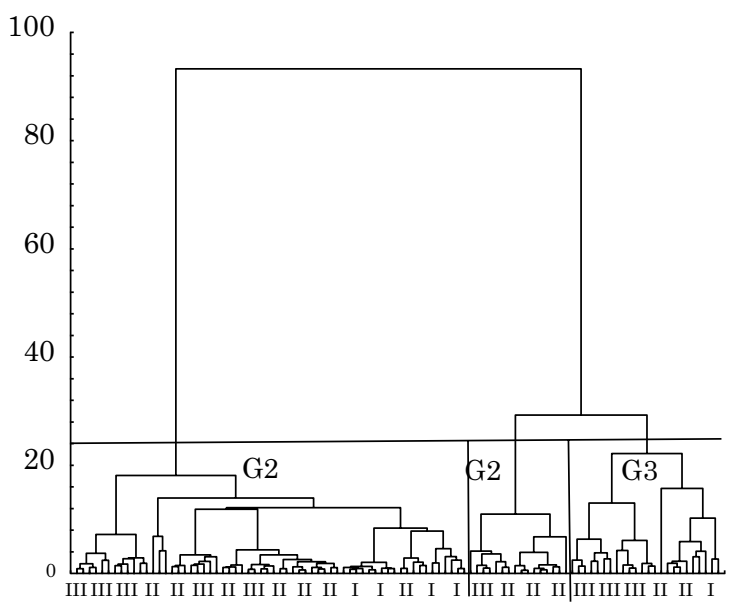

(e)

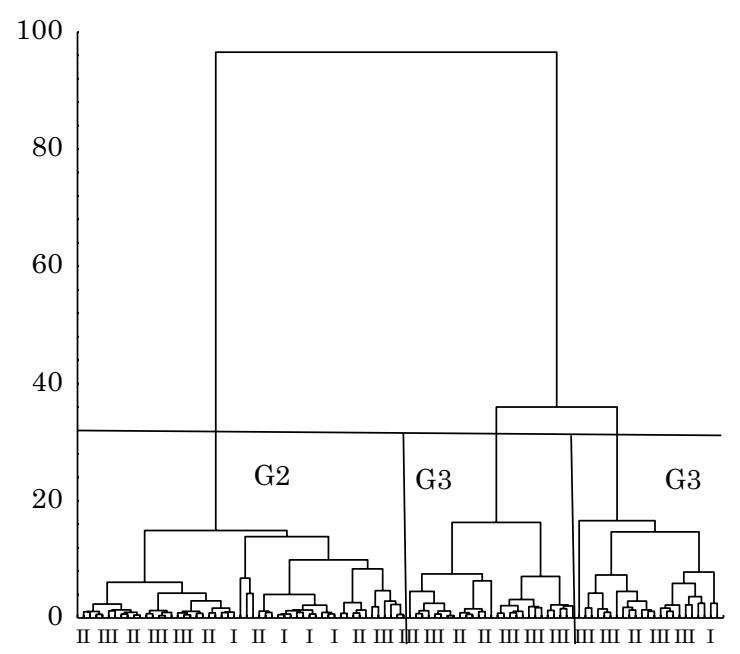

(f)

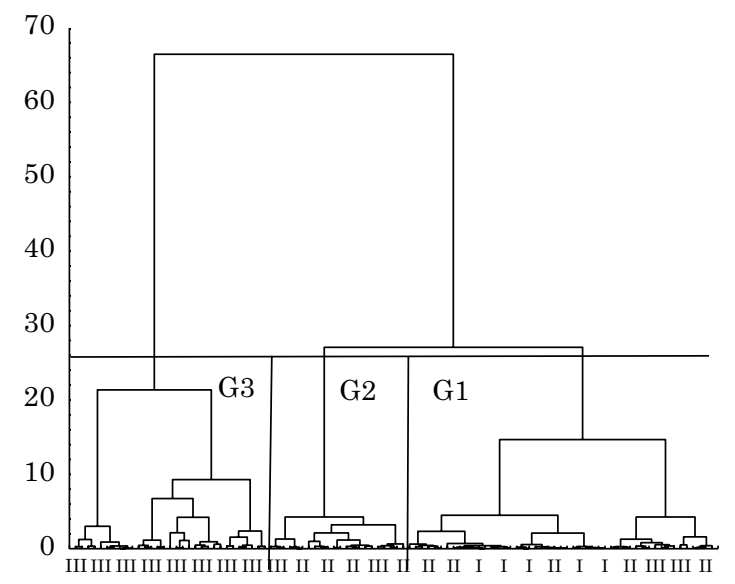

Figura 4. Análise de agrupamento (dendograma) dos atributos químicos, granulométricos e sua relação com a suscetibilidade magnética (SM) em duas profundidades (0,00-0,20 e 0,60-0,80 m), em uma transeção, na separação das superfícies geomórficas. Separação das superfícies por meio dos atributos químicos, granulométricos e SM (a, d), químico e SM (b, e) e granulométricos e SM (c, f). 
e segmentos de vertentes deve levar em conta a escolha de atributos covariativos com o material de origem ou relacionados com os processos de formação do solo (Zawadzki et al., 2012; Matias et al., 2013; Siqueira et al., 2015), como a SM e análise estatística adequada, que permitem identificar os corpos naturais de solos na paisagem.

Ao analisar vários perfis, levando em consideração a posição da vertente, Matias et al. (2013) concluíram que solos taxonomicamente iguais, porém em diferentes compartimentos da paisagem, apresentaram valores distintos para os atributos estudados, indicando que os modelos de paisagem e a susceptibilidade magnética podem ser viáveis, como técnica de campo, para auxiliar no detalhamento da variação dos atributos do solo. Zawadzki et al. (2012) concluíram que em área manejada de forma antropogênica, a análise do comportamento e distribuição espacial da SM pode ser útil para distinguir a influência do material de origem, sendo possível investigar onde os volumes de solo com elevada SM situam-se no perfil do solo e desse modo investigar qual o tipo característico do solo.

A distância euclidiana na análise de agrupamento variou de 18 a 32 nas duas profundidades estudadas (Figura 3). Com base no conjunto dos atributos químicos e granulométricos, foi possível ordenar os dados em três grupos (G1, G2 e G3), correspondendo às superfícies geomórficas I, II e III. Esses resultados indicam que a técnica da análise multivariada pode ser utilizada para confirmar a teoria de Ruhe (1967) e Daniels et al. (1971).

Na figura 4, observou-se o mesmo comportamento da figura 3 ; porém, a introdução da SM na análise, juntamente com os atributos químicos e granulométricos, possibilitou maior representatividade quando comparado à figura 3. Esse comportamento confirma os resultados de Zawadzki et al. (2012) e Matias et al. (2013), os quais descreveram em seus trabalhos a eficiência da SM na separação das superfícies geomórficas.

Os resultados deste estudo indicaram que a forma de coleta do solo (profundidade e distribuição) e a análise das variáveis, quando agrupadas, possibilitam a distinção de ambientes, permitindo a implementação de estratégias de manejo diferenciadas. Essa informação corrobora com a afirmativa de Campos et al. (2012a) de que essa técnica permite agrupar variáveis com características semelhantes entre si e com aumento de variabilidade entre os agrupamentos formados.

De acordo com Siqueira et al. (2010a, 2015), Campos et al. (2012a) e Sanchez et al. (2012), a separação dos ambientes permite melhorias no planejamento agrícola. Campos et al. (2012a), estudando as relações entre os atributos do solo, a topografia e a vegetação na Amazônia brasileira, destacaram a análise de agrupamento como uma ferramenta bastante eficiente no estudo de múltiplos fatores ambientais de naturezas distintas. Segundo Cruz et al. (2011) e Campos et al. (2012b), as análises de distribuição espacial que consideram os diferentes solos nas paisagens com o uso da estatística multivariada podem contribuir para obter o melhor entendimento do ambiente. As técnicas de estatística multivariada levam em consideração a totalidade das variáveis, pois uma depende da outra, e as informações são fornecidas pelo conjunto e não individualmente (Cruz et al., 2011).

\section{CONCLUSÕES}

Os limites matemáticos da técnica Split Moving Windows Dissimilarity Analysis (SMWDA), utilizando as informações da suscetibilidade magnética, ficaram próximos com os limites de campo identificados com base nos modelos de paisagem.

A utilização conjunta da suscetibilidade magnética, dos modelos matemáticos e de paisagem permitiu identificar diferentes áreas de manejo, locais com diferentes teores de argila e níveis de fertilidade do solo.

A susceptibilidade magnética pode ser adotada como alternativa para identificar e mapear unidades de manejo.

\section{REFERÊNCIAS}

Barris MR, Marques Júnior J, Panosso AR, Siqueira DS, Scala Junior NLA. Magnetic susceptibility to identify landscape segments on a detailed scale in the region of Jaboticabal, São Paulo, Brazil. R Bras Ci Solo. 2012;36:1073-82.

Berg MVD. Transect.For, listagem na língua Fortran. Piracicaba: ESALQ/USP, Departamento de Ciências do Solo; 1988.

Campos MCC, Ribeiro MR, Souza Júnior VS, Ribeiro Filho MR, Almeida MC. Relações solo-superfície geomórfica em uma topossequência várzea-terra firme na região de Humaitá (AM). R Bras Ci Solo. 2012a;36:325-36.

Campos MCC, Marques Júnior J, Souza ZM, Siqueira DS, Pereira GT. Discrimination of geomorphic surfaces with multivariate analysis of soil attributes in sandstone - basalt lithosequence. $\mathrm{R}$ Ci Agron. 2012b;43:429-38.

Cano Gonzalez, ME, Cordova-Fraga T, Sosa M, Bernal-Alvarado $\mathrm{J}$, Baffa O. Understanding the magnetic susceptibility measurements by using an analytical scale. Eur J Phys. 2008;29:345-54.

Carneiro AAO, Touso AT, Baffa O. Avaliação da susceptibilidade magnética usando uma balança analítica. Quím Nova. 2003;26:952-6.

Cruz JS, Assis Júnior RN, Matias SSR, Camacho-Tamayo JH. Spatial variability of an Alfisol cultivated with sugarcane. Ci Invest Agron. 2011;38:155-64. 
Cunha P, Marques Júnior J, Curi N, Pereira GT, Lepsch IF. Superfícies geomórficas e atributos de Latossolos em uma sequência arenítico-basáltica da região de Jaboticabal (SP). R Bras Ci Solo. 2005;29:81-90.

Dalrymple JB, Blong RJ, Conacher AJ. A hipothetical nine unit land a surface model. Z. Geomorphol. 1968;12:60-76.

Daniels RB, Gamble EF, Cady JG. The relation between geomorphology and soil morphology and genesis. Adv Agron. 1971;23:51-87.

Empresa Brasileira de Pesquisa Agropecuária - Embrapa. Centro Nacional de Pesquisa de Solos. Sistema brasileiro de classificação de solos. 2a.ed. Rio de Janeiro: 2006.

Empresa Brasileira de Pesquisa Agropecuária - Embrapa. Centro Nacional de Pesquisa de Solos. Manual de métodos de análise de solo. Rio de Janeiro:1997.

Erdős L, Gallé R, Bátori Z, Papp M, Körmöczi L. Properties of shrubforest edges: A case study from South Hungary - Cent. Eur J Biol. 2011;6:639-58.

Erdős L, Méri Á, Bátori Z, Gallé R, Körmöczi L. North-south facing vegetation gradients in the Villány Mts: A case study on the population and the community level. Pak J Bot. 2012;44:927-32.

Erdős L, Bátori Z, Morschhauser T, Körmöczi L. Ecological boundaries at different scales: testing the moving split window analysis using artificial and field data. Pol. J. Ecol. 2013;61:319-28

Espinar J, Ross MS, Sah JP. Pattern of nutrient availability and plant community assemblage in Everglades tree islands, Florida USA. Hydrobiologia. 2011;667:89-99.

Goldthorpe JH. Women and class analysis: In defence of the conventional view. Sociology. 1983;17:465-88.

Hair JF, Anderson RE, Tatham RL, Black W. Análise multivariada de dados. Porto Alegre: Bookman; 2005.

Instituto de Pesquisas Tecnológicas do Estado de São Paulo - IPT. Mapa Geológico do Estado de São Paulo. São Paulo: 1981. v. 1. Escala 1:500.000.

Matias SSR, Marques Júnior J, Siqueira DS, Pereira GT. Modelos de paisagem e susceptibilidade magnética na identificação e caracterização do solo. Pesq Agropec Trop. 2013;43:93-103.

Meireles HT, Marques Júnior J, Campos MCC, Pereira GT. Relações solo-paisagem em topossequência de origem basáltica. Pesq Agropec Trop. 2012:42:129-36

Raij Bvan, Andrade JC, Cantarella H, Quaggio J. Análise química para avaliação da fertilidade de solos tropicais. São Paulo: Instituto Agronômico de Campinas; 2001.

Ross MS, Sah JP. Forest resource islands in a sub-tropical marsh: Soil-site relationships in everglades hardwood hammocks. Ecosystems. 2011;14:632-45.

Ruhe RV. Quaternary landscape in Iowa Ames. Ames: State University Press; 1969.

SAS. Statistical Analysis System for Windows: Computer program manual. Cary: 2007.
Sanchez RB, Marques Júnior J, Pereira GT, Baracat Neto J, Siqueira DS, Souza ZM. Mapeamento das formas do relevo para estimativa de custos de fertilização em cana-de-açúcar. Eng Agric. 2012;32:280-92

Santos HL, Marques Júnior J, Matias SSR, Siqueira DS, Pereira GT. Suscetibilidade magnética na identificação de compartimentos da paisagem em uma vertente. R Bras Ci Agrár. 2011;6:710-6

Scalon MC. Mapeando estratos: Critérios para escolha de uma classificação. R Ci Sociais. 1998;41:337-75.

Siqueira DS, Marques Jr. J, Pereira GT, Teixeira DB, Vasconcelos V, Carvalho Júnior OA, Martins ES. Detailed mapping unit design based on soil -landscape relation and spatial variability of magnetic susceptibility and soil color. Catena. 2015; doi.org/10.1016/j.catena.2015.07.010

Siqueira DS, Marques Júnior J, Pereira GT. The use of landforms to predict the variability of soil and orange attributes. Geoderma. 2010a;155:55-66.

Siqueira DS, Marques Júnior J, Matias SSR, Barrón V, Torrent J, Baffa O, Oliveira LC. Correlation of properties of Brazilian Haplustalfs with magnetic susceptibility measurements. Soil Use Manage. 2010b;26:425-31.

Siqueira DS, Marques Jr. J, Pereira GT, Teixeira DB, Vasconcelos V, Carvalho Júnior OA, Martins ES. Detailed mapping unit design based on soil-landscape relation and spatial variability of magnetic susceptibility and soil color. Catena. 2015; http://dx.doi.org/10.1016/j.catena.2015.07.010

Sneath PH, Sokal RR. Numerical taxonomy: The principles and practice of numerical classification. San Francisco: W. H. Freeman; 1973

Sousa GB, Martins Filho MV, Matias SSR. Perdas de solo, matéria orgânica e nutrientes por erosão hídrica em uma vertente coberta com diferentes quantidades de palha de cana-de-açúcar em Guariba - SP. Eng Agríc. 2012;32:490-500.

Souza Junior IG, Costa ACS, Vilar CC, Hoepers A. Mineralogia e susceptibilidade magnética dos óxidos de ferro do horizonte B de solos do Estado do Paraná. Ci Rural. 2010;40:513-9.

Torrent J, Barron V, Liu QS. Magnetic susceptibility changes in relation to pedogenesis in a Xeralf chronosequence in northwestern Spain. Eur J Soil Sci. 2010;61:161-73.

Torrent J, Barrón V, Liu QS. Magnetic enhancement is linked to and precedes hematite formation in aerobic soil, Geophys Res Lett. 2006;33:1-4.

Webster R. Automatic soil-boundary location from transect data. Math Geol. 1973;5:27-37.

Webster R. Optimally partitioning soil transects. J Soil Sci. 1978;29:388-402

Xu D, Xu X, Xie Y, Wang K. Dynamics of sandy desertification and detection of sandy land/steppe boundary: Vegetation and soil properties. Polish J Ecol. 2012;60:251-63.

Zawadzki J, Magiera T, Fabijańczyk P, Kusza G. Geostatistical 3-dimensional integration of measurements of soil magnetic susceptibility. Environ Monit Assess. 2012;184:3267-78. 